\title{
Master of Science in Nursing students' expectations to participate in nursing research-related tasks in clinical practice after completing their education - A cross-sectional survey
}

\author{
Connie Berthelsen*, Bente Martinsen, Marianne Vamosi \\ Research Unit of Nursing and Healthcare, Institute of Health, Nursing, Aarhus University, Denmark
}

Received: November 7, 2019

DOI: $10.5430 /$ jnep.v10n5p1
Accepted: December 17, 2019 Online Published: December 26, 2019

URL: https://doi.org/10.5430/jnep.v10n5p1

\begin{abstract}
Objective: To describe Master of Science in Nursing students' expectations to participate in nursing research-related tasks in daily clinical practice after completing their education.

Methods: To support this assumption a descriptive cross-sectional study was conducted to describe Master of Science in nursing students' expectations to participate in nursing research-related tasks in daily clinical practice after completing their education. Data were collected using a 41-item structured questionnaire.

Results: A convenience sample of Master of Science in Nursing students $(n=116)$ was recruited during their third semester and $92(79.3 \%)$ students replied the questionnaire. The results showed how $91.3 \%$ of the students expressed high expectations regarding their possibilities for participation in nursing research-related tasks in clinical practice. However, 64.1\% doubted that time and resources would be allocated to nursing research.

Conclusions: The key motivator for the students was to improve patient care, further develop clinical practice, and strengthen the nursing profession. However, the literature suggests that colleagues and the nursing management in clinical practice impose certain barriers that prevent nurses from participating in research.
\end{abstract}

Key Words: Cross-sectional study, Clinical practice, Education, Master of science in nursing students, Research utilization

\section{INTRODUCTION}

During recent decades, the need for evidence-based nursing practice to improve patient care and outcomes has increased. $^{[1]}$ However, nurses' participation in research in clinical practice as well as utilization and implementation of nursing research, is still in its infancy. ${ }^{[2,3]}$ Many barriers against nurses' research utilization such as lack of authority to change practice, ${ }^{[4,5]}$ lack of support by colleagues, ${ }^{[3,6]}$ medical doctors ${ }^{[3]}$ and nurse managers, ${ }^{[7,8]}$ a lack of academic role models ${ }^{[2,9]}$ and lack of time ${ }^{[2,8,9]}$ has been well documented. A busy daily practice is also a hindrance for nurses research utilization, ${ }^{[10]}$ where nurse-patient ratio is decreasing ${ }^{[11]}$ as well as an increase in shortage of nursing staff due to financial constraints on healthcare. ${ }^{[12]}$ Faced with the fact that they cannot provide all necessary care to their patients, nurses prioritise providing the best possible care

\footnotetext{
*Correspondence: Connie Berthelsen; Email: cb@ph.au.dk; Address: Research Unit of Nursing and Healthcare, Institute of Health, Nursing, Aarhus University, Denmark. 
with the available resources, leaving research utilization as a secondary task. ${ }^{[3,8]}$

Nurses' lack of knowledge on research and academic competencies to perform research-related tasks is another known barrier for research utilization and a cause to the limited extent of evidence-based practice in clinical nursing. ${ }^{[13-15]}$ To overcome the barrier concerning lack of knowledge a proportion of nurses choose to require an academic education on master level, where the nurses expect to gain a stronger and broader knowledge of academic knowledge and competencies. ${ }^{[16,17]}$ Accordingly, the curriculum of the Master of Science in Nursing (MSN) education states that students acquire comprehensive knowledge on research methodologies and methods used in nursing. Choosing to undertake a postgraduate education builds on several motivational factors apart from the possibility to strengthen academic knowledge. ${ }^{[16,17]}$ Where some nurses identify the possibilities to improve their career change or promotional prospects others choose an academic education to increase their earning potential. ${ }^{[16]}$ In a survey of graduates of post-registration Bachelor's and Master's courses in nursing Hardwick and Jordan ${ }^{[18]}$ explains how the nurses reasons for undertaking a postgraduate education circles around extending personal knowledge of nursing, acquire research skills, upgrade academic qualifications, and the prospects of being promoted. Zahran ${ }^{[19]}$ conducted an ethnographic study over two years in Jordanian hospitals to explore the key motivational factors for nurses to undertake a Master's degree and their perceived impact on practice. In the same study the 37 included nurses reported how self-development, raising the status of nursing, broadening career opportunities and developing practice was the main motivational factors for undertaking a master's degree. ${ }^{[19]}$

In Denmark, the MSN education is a four-semester (twoyear) postgraduate program provided in three of five Danish universities. At the theoretical level, the participants on the MSN education receives knowledge about research-related tasks in nursing. The MSN education aims for mid-career professionals, opposed to masters purely by research degrees, ${ }^{[16]}$ which means that students attending the MSN education already have achieved nursing experience in clinical practice. Though the MSN-students are aware of life in a busy daily practice, where time and resources are limited, no studies were found about their expectations to use their newly acquired skills postgraduate in clinical practice. In order to prepare the students for academic life after postgraduate education as well as preparing clinical practice settings for their arrival, knowledge is needed of the MSN-students' considerations around their utilization of research in practice.
The aim of this study was therefore to describe Master of Science in Nursing students' expectations to participate in nursing research-related tasks in daily clinical practice after completing their education.

\section{MeTHODS}

\subsection{Study design}

A descriptive cross-sectional study ${ }^{[20]}$ as conducted with MSN-students in a Danish University. This design was chosen to provide an immediate overview of the MSN-students' expectations to participate in research-related tasks after their Master of Science education at a defined point of time - just before graduation.

\subsection{Setting and participants}

The participants of this study consisted of MSN-students in their third semester divided on two campuses (A and B) in a Danish university. All MSN-students had previously been educated in qualitative and quantitative methods, as well as critical thinking of nursing and nursing theories. The MSN-students $(\mathrm{N}=116)$ were recruited through convenience sampling during a teaching session in both campuses in October 2017. The teaching session regarding the barriers and possibilities of nursing research in clinical practice and was performed by the first author.

\subsection{The questionnaire}

A questionnaire was specifically constructed for the purpose of this study. The construction of the questionnaire was based on a systematic literature search in PubMed/MEDLINE and CINAHL in April 2017, using the keywords "questionnaire", "clinical practice", "master degree", "post-graduate" and "research" combined with "barriers", "capacity", "interest", "knowledge", "motivation", "utilization", "activities", and "tasks". A total of 18 studies were selected for full-text reading and six studies with eligible questionnaires ${ }^{[9,16,21-24]}$ were included in formulating the items for our questionnaire. The six studies had been conducted as surveys with various designs: Three of the six studies had used already validated instruments ${ }^{[21-23]}$ while the three other studies examined face- and content validity of their questionnaires. ${ }^{[9,16,24]}$

\subsubsection{Description of the questionnaires and extraction of items}

The development of our questionnaire was based on 37 items, which were extracted from the six eligible studies included in the systematic literature search. ${ }^{[9,16,21-24]}$

The BARRIERS: The Barrier to Research Utilization Scale $^{[22]}$ is a 29-item instrument to assess clinicians', administrators' and academics' perceptions of barriers to the utilization of research findings in practice, rated on a scale 
from 1 (to no extent) to 4 (to a great extent). The instrument is divided into four factors and has individual alpha coefficients, measuring: 1) the nurses' research values, skills and awareness (.80); 2) setting barriers and limitations (.80); 3 ) the qualities of the research (.72); and 4) the presentation and accessibility of the research (.65) (Funk et al., 1991). Six items from the BARRIERS scale were included in our questionnaire in the second theme covering the MSN-students' expectations to participate in nursing research-related tasks in clinical practice.

A combination of the 47-item RAI (Research Attitudes Inventory) and the 27-item CBISQ (Cognitive-Behavioral Intervention Study Questionnaire) constructed by Jacobson and colleagues ${ }^{[23]}$ was used to examine the effect of personal and professional characteristics and attitudes about nursing research on staff nurses' participation in a clinical nursing research project. Reliability analyses revealed Cronbach's alpha statistics of .86 for RAI and .82 for CBISQ. ${ }^{[23]}$ Two items were included in our questionnaire in the second theme covering the MSN-students' expectations to participate in nursing research-related tasks in clinical practice.

Akerjordet and colleagues ${ }^{[21]}$ present the 59-item instrument developed to determine the clinical nurses' interest in and motivation for research. Internal consistency between the items and the categories using Cronbach's alpha was .99 for the overall questionnaire. ${ }^{[21]}$ Four items were extracted from this instrument and included in our questionnaire: Two items were used in the first theme covering the setting and positions of the MSN-students employment, one item was used in theme four on MSN-students' expectation to further develop their research-related knowledge and competencies, and one item was included covering theme six on the MSN-students' sources of motivation.

Three items were extracted from a six-item measurement presented by Drennan ${ }^{[16]}$ and included in our questionnaire to identify the academic and professional destination of nurses with Masters' degrees in nursing in the first theme. Drennan' ${ }^{[16]}$ measurement did not undergo an alpha-coefficient measure. However, face and content validity of the questions were examined by a cognitive interviewing technique in a selected sample of the respondents.

Parahoo's ${ }^{[24]} 11$-item questionnaire, constructed through a review of the literature on research utilization and research activities of nurses to report nurses' attitudes to research, was used for four items in our questionnaire in theme two on the MSN-students' expectations to participate in nursing research-related tasks in clinical practice. No Cronbach's alpha calculation was made; however, a panel of experts experienced in research examined content validity of the questions. ${ }^{[24]}$

Berthelsen and Hølge-Hazelton ${ }^{[9]}$ constructed a 24-item questionnaire to determine the self-perceived knowledge, competencies, interests and motivation regarding research among orthopaedic nurses. Two orthopedic nurses examined face and content validity concerning the content and consistency of the questionnaire. ${ }^{[9]} 18$ items were included in our questionnaire. One item was included in theme two on the MSN-students' expectations to participate in nursing research-related tasks in clinical practice, one item was used in theme five concerning the MSN-students' expectation on research collaboration, and 16 items were used in theme three covering the MSN-students' expectations to engage in specific nursing research-related tasks.

\subsubsection{Description of the final questionnaire}

The final questionnaire covered six themes overarching 41 items consisting of the 37 items from the six included studies and four generic items covering age, years as educated nurse, years in clinical practice and education after nursing studies.

The first theme included nine items covering the demographic characteristics of the MSN-students. ${ }^{[16,21]}$ The second theme covered 13 items on the MSN-students' expectations to participate in nursing research-related tasks in clinical practice. ${ }^{[9,22-24]}$ The third theme of MSN-students' expectations to engage in specific nursing research-related tasks was covered through 16 items. ${ }^{[9]}$ In theme four, the MSN-students' expectation to further develop their researchrelated knowledge and competencies was covered through one item. ${ }^{[21]}$ The MSN-students' expectations of research collaboration $^{[9]}$ and their sources of motivation ${ }^{[21]}$ were included in theme five and six, through one item respectively.

All questions on demographics characteristics in them one were provided with a dichotome answer possibility, while theme two to six were provided multiple-choice answer possibilities.

\subsubsection{Validation of the final questionnaire}

All three authors assessed content and construct validity to examine whether themes and items covered the full range of issues being measured. All authors, as well as $24 \mathrm{MSN}$ students enrolled in connection with the last author's second semester teaching session on questionnaires in September 2016, investigated face validity to check if the items were logically linked to the objectives of the study.

\subsection{Data collection}

Data were collected among MSN-students at a third semester teaching session regarding the barriers and possibilities of nursing research in clinical practice in October 2017. The first author, who performed the teaching session, handed out 
the self-report questionnaires in paper format to the MSNstudents at the beginning of the session and allowed the students 15 minutes to complete them alone. To ensure anonymity the MSN-students were reminded to deposit the replied questionnaires in a box by the class room blackboard before the first author returned.

\subsection{Data analysis}

All data were analyzed using descriptive statistics and STATA software (12.0). The results were presented as numbers and percentages for the total group of participants. Since our study was conducted as a cross-sectional survey examining the MSN-students' expectations on a certain point of time, no comparisons were calculated in the analysis or in results.

\subsection{Ethical considerations}

The Danish Data Protection Agency (AU file number 62908; unique AU-id 310) approved the study. During recruitment, the MSN-students received information orally and in writing about their legal and ethical rights according to the Helsinki Declaration before consenting to participate. The MSNstudents did not sign a consent form however; their completion of the questionnaire was taken as consent to participate.

\section{Results}

In Campus A N = 56 Master of Science in Nursing (MSN) students were enrolled in the education and all students were present during the teaching session, where a total of 48 (85.7\%) MSN-students replied the questionnaire. In Campus $\mathrm{B} \mathrm{N}=60 \mathrm{MSN}$-students were enrolled and present during the teaching session, where 44 (73.3\%) MSN-students replied the questionnaire. The total number of completed questionnaires was 92 out of 116 providing a response rate of $79.3 \%$ (see Table 1).

Table 1. Data collection and replied questionnaires

\begin{tabular}{lll}
\hline & $\begin{array}{l}\text { Students enrolled } \\
\text { in the MSN, N }\end{array}$ & $\begin{array}{l}\text { Total amount of replied } \\
\text { questionnaires, N (\%) }\end{array}$ \\
\hline Campus A & 56 & $48(85.7 \%)$ \\
Campus B & 60 & $44(73.3 \%)$ \\
Total & 116 & $92(79.3 \%)$ \\
\hline
\end{tabular}

\subsection{Demographic characteristics of the MSN-students}

A total of 116 students were enrolled on the Master of Science in Nursing education and 92 students agreed to participate in the cross-sectional survey, resulting in a participation rate of $79.3 \%$ (see Table 2 ).

The age range of the majority of the MSN-students was between 25 and 39 years $(79.4 \%)$. Two participants $(2.8 \%)$ were aged between 18 and 24, and 20 participants (21.7\%) were aged between 35 and 39 years. Only 9 (8.7\%) MSNstudents were aged $\geq 45$ years. The majority of MSNstudents had been qualified nurses for $0-4$ years $(43.5 \%)$, whereas $26(28.3 \%)$ MSN-students had been qualified for 5-9 years, and 14 (15.2\%) MSN-students for 10-14 years (see Table 2).

A total of 33 (35.9\%) MSN-students had further improved their own skills or qualifications after their nursing education: at Bachelor level $(\mathrm{N}=21 ; 22.8 \%)$, at Master level other than nursing $(\mathrm{N}=2 ; 6.1 \%)$, or by completing education programs other than nursing $(\mathrm{N}=13 ; 39.4 \%)$ (see Table 2$)$.

Table 2. Demographic characteristics of the MSN-students $(\mathrm{N}=92)$

\begin{tabular}{ll}
\hline Variable & $\mathbf{N} \mathbf{( \% )}$ \\
\hline Total & $\mathbf{9 2 ( 1 0 0 . 0 \% )}$ \\
\hline Age (years) & \\
$<18$ & 0 \\
$18-24$ & $2(2.8 \%)$ \\
$25-29$ & $34(37.0 \%)$ \\
$30-34$ & $19(20.7 \%)$ \\
$35-39$ & $20(21.7 \%)$ \\
$40-44$ & $9(10.8 \%)$ \\
$45-49$ & $4(4.3 \%)$ \\
$\geq 50$ & $4(4.3 \%)$ \\
No. of years qualified as nurse & \\
$0-4$ & $40(43.5 \%)$ \\
$5-9$ & $26(28.3 \%)$ \\
$10-14$ & $14(15.2 \%)$ \\
$15-19$ & $7(7.6 \%)$ \\
$20-24$ & $4(4.3 \%)$ \\
$\geq 25$ & $1(1.1 \%)$ \\
No. of years in clinical practice & \\
$0-4$ & $47(51.1 \%)$ \\
$5-9$ & $23(25.0 \%)$ \\
$10-14$ & $13(14.1 \%)$ \\
$15-19$ & $5(5.4 \%)$ \\
$20-24$ & $3(3.2 \%)$ \\
$\geq 25$ & $1(1.1 \%)$ \\
Continuing professional development after nursing school \\
No & $59(64.1 \%)$ \\
Yes & $33(35.8 \%)$ \\
Bachelor-level degree & $21(22.8 \%)$ \\
\hline & $2(6.1 \%)$ \\
\hline & $13(39.4 \%)$ \\
\hline &
\end{tabular}

Among the MSN-students, the mean length of experience in clinical practice was $0-4$ years $(\mathrm{N}=47 ; 51.1 \%)$. Twentythree $(25.0 \%)$ MSN-students had spent 5-9 years in clinical 
practice, $13(14.1 \%)$ had spent $10-14$ years in clinical practice, and 9 (8.7\%) students had been working for $\geq 15$ years in clinical practice before being enrolled at the Master of Science in Nursing education (see Table 2).
Although the Master of Science in Nursing education is considered to be a full-time activity, the results showed that 77 (83.7\%) MSN-students were working while enrolled (see Table 3).

Table 3. Employment during and after the MSN-education $(\mathrm{N}=92)$

\begin{tabular}{|c|c|c|}
\hline & $\begin{array}{l}\text { Employment during their MSN education } \\
\text { N (\%) }\end{array}$ & $\begin{array}{l}\text { Employment after their MSN education } \\
\text { N (\%) }\end{array}$ \\
\hline No & $15(16.3 \%)$ & $70(76.1 \%)$ \\
\hline Yes & $77(83.7 \%)$ & $22(23.9 \%)$ \\
\hline \multicolumn{3}{|l|}{ Setting } \\
\hline Home care & $15(19.5 \%)$ & $4(18.2 \%)$ \\
\hline Hospital & $53(68.8 \%)$ & $16(72.3 \%)$ \\
\hline Educational sector & $1(1.3 \%)$ & - \\
\hline Private institutions & $8(10.4 \%)$ & $2(9.1 \%)$ \\
\hline \multicolumn{3}{|l|}{ Position } \\
\hline Department head nurse & - & - \\
\hline Nurse manager & - & - \\
\hline Clinical nurse specialist & $2(2.6 \%)$ & $3(13.6 \%)$ \\
\hline Clinical development nurse & $2(2.6 \%)$ & $1(4.5 \%)$ \\
\hline Clinical educational nurse & $1(1.3 \%)$ & $1(4.5 \%)$ \\
\hline Registered nurse & $61(79.2 \%)$ & $12(54.5 \%)$ \\
\hline Researcher assistant & $4(5.2 \%)$ & $3(13.6 \%)$ \\
\hline Teacher & $5(6.5 \%)$ & - \\
\hline Other & $3(3.9 \%)$ & $2(9.1 \%)$ \\
\hline \multicolumn{3}{|l|}{ Working hours } \\
\hline Full time $(37 \mathrm{~h})$ & $4(5.2 \%)$ & $8(36.4 \%)$ \\
\hline Part time $(30-35 \mathrm{~h})$ & $3(3.9 \%)$ & $7(31.8 \%)$ \\
\hline Part time $(\geq 29 \mathrm{~h})$ & $21(27.3 \%)$ & $3(13.6 \%)$ \\
\hline Substitute & $48(62.3 \%)$ & $4(18.2 \%)$ \\
\hline \multicolumn{3}{|c|}{ Working hours on average/per week } \\
\hline Range (x-x), & $(1-37)$ & - \\
\hline Mean/median & $11 / 8$ & - \\
\hline
\end{tabular}

Among this group of MSN-students, $\mathrm{N}=53$ (68.8\%) were employed in hospitals, whereas $15(19.5 \%)$ were employed in home care. The mean workload among the MSN-students was as follows: $\mathrm{N}=28$ (36.4\%) reported their workload to be between 29 and 37 hours a week and $\mathrm{N}=48$ (62.3\%) reported their workload to be less than 29 hours per week. Only four (5.2\%) MSN-students worked full-time during their studies and the majority of MSN-students (62.3\%) worked varying hours as substitutes (see Table 3).

Only 22 (23.9\%) of the students were secured employment after completing the Master of Science in Nursing education. Of the $22 \mathrm{MSN}$-students, $\mathrm{N}=16(72.7 \%)$ were secured employment in hospitals and four $(18.2 \%)$ in home care. The positions counted $12(54.5 \%) \mathrm{MSN}$-students as registered nurses, three (13.6\%) as research assistants, two (9.1\%) in clinical development and education and two $(9.1 \%)$ in other positions. $\mathrm{N}=8(36.4 \%) \mathrm{MSN}$-students had been secured employment in full-time positions and $10(45.4 \%)$ in parttime positions between 29 and 35 hours per week (see Table $3)$.

\subsection{MSN-students' expectations to participate in nurs- ing research-related tasks in clinical practice}

The Master of Science in Nursing students were asked about their expectations regarding their possibilities for engaging in nursing research-related tasks in clinical practice (see Table 4). 
Table 4. MSN-student's expectations to participate in nursing research-related tasks

\begin{tabular}{lll}
\hline Total & N = 92 (\%) \\
\hline I expect that: & $\begin{array}{l}\text { To no or a } \\
\text { little extend }\end{array}$ & $\begin{array}{c}\text { To a moderate or } \\
\text { a great extend }\end{array}$ \\
\hline There will be a need for nursing research related tasks in my unit & $8(8.7 \%)$ & $84(91.3 \%)$ \\
Nursing research related tasks will be necessary in my unit & $2(2.2 \%)$ & $90(98.8 \%)$ \\
My colleagues will accept and support my engagement in nursing research related tasks & $32(34.8 \%)$ & $60(65.2 \%)$ \\
My nursing colleagues will spend time in their daily work to engage in nursing research related & $49(53.3 \%)$ & $43(46.7 \%)$ \\
tasks with me & $21(22.8 \%)$ & $71(77.2 \%)$ \\
My nurse leaders will accept my time spend on nursing research related tasks & $67(72.8 \%)$ \\
My organization and head managers will accept my time spend on nursing research related tasks & $25(27.2 \%)$ \\
My unit will reward nurses who engage in nursing research related tasks & $62(67.4 \%)$ & $30(32.6 \%)$ \\
There will be nurses present for consultation with a research background & $50(54.3 \%)$ & $42(45.7 \%)$ \\
My unit will have resources like time and money for nursing research related tasks & $59(64.1 \%)$ & $33(35.9 \%)$ \\
There will be time to read nursing research articles & $55(60.0 \%)$ & $37(40.2 \%)$ \\
There will be time to participate in journal clubs & $53(57.6 \%)$ & $39(42.4 \%)$ \\
Nursing research related tasks will lead to an improvement of patient care in the unit & $1(1.1 \%)$ & $91(98.9 \%)$ \\
Nursing research related tasks will lead to a strengthening of the nursing profession in the unit & $3(3.3 \%)$ & $89(96.7 \%)$ \\
\hline
\end{tabular}

The tasks with the greatest number of responses of a high to a moderate degree were: That nursing research-related tasks will lead to an improvement of patient care in the unit $(\mathrm{N}=91 ; 98.9 \%)$, a need for nursing research-related tasks will be necessary in my unit $(\mathrm{N}=90 ; 98.8 \%)$, nursing research-related tasks will lead to a strengthening of the nursing profession in the unit $(\mathrm{N}=89 ; 96.7 \%)$, and a need for nursing research-related tasks in my unit $(\mathrm{N}=84 ; 91.3 \%)$ (see Table 4). The nursing research-related tasks with the highest number of responses of no to a lesser extent were: My unit will reward nurses who engage in nursing researchrelated tasks $(\mathrm{N}=62 ; 67.4 \%)$, my unit will have resources like time and money for nursing research-related tasks ( $\mathrm{N}$ $=59 ; 64.1 \%)$, there will be time to read nursing research articles $(\mathrm{N}=55 ; 60.0 \%)$ and there will be time to participate in journal clubs $(\mathrm{N}=53 ; 57.6 \%)$ (see Table 4$)$.

\subsection{MSN-students' expectations to participate in spe- cific nursing research-related tasks}

The following nursing research-related tasks showed the highest rate of expectation: Conducting literature reviews in databases $(\mathrm{N}=81 ; 88.0 \%)$, getting an idea for a research project $(\mathrm{N}=80 ; 87.0 \%)$, appraise and analyse research papers in Danish $(\mathrm{N}=77 ; 83.7 \%)$, and in English $(\mathrm{N}=75$; $81.5 \%$ ) (see Table 5).

The nursing research-related tasks with the lowest rate of expectations were: Use statistical analysis $(\mathrm{N}=27 ; 29.3 \%)$, write a scientific article $(\mathrm{N}=35 ; 38.0 \%)$, apply for funding $(\mathrm{N}=39 ; 42.3 \%)$ and develop clinical guidelines $(\mathrm{N}=41$; $44.5 \%$ ) (see Table 5).

6

\subsection{MSN-students' expectations to further develop their} research knowledge and competencies

Apart from participating in nursing research-related tasks, 82 students $(89.1 \%)$ answered "yes" to a need for further knowledge and competencies (see Table 6).

MSN-students confirmed knowledge and competencies of qualitative research methods $(\mathrm{N}=60 ; 73.2 \%)$ and qualitative analysis $(\mathrm{N}=63 ; 76.8 \%)$ as their primary interest for further development. Statistical analysis was expressed as a future need by 27 (32.9\%) of the MSN-students; 44 (53.6\%) MSNstudents expected to develop their knowledge of research design; 35 (42.7\%) expected to develop further knowledge and competencies in quantitative research methods, and 34 (41.5\%) expressed expectations for further development of their knowledge in research methodology. Only two (2.2\%) of the MSN-students did not expect further development of their research knowledge and competencies (see Table 6).

\subsection{MSN-students' expectations of research collabora- tion and sources of motivation}

Expectations of being able to perform nursing researchrelated tasks in collaboration with research staff after completing their Master of Science in Nursing education was considered important by 73 (79.3\%) of the MSN-students (see Table 7).

The MSN-students expected to collaborate with $\mathrm{PhD}$ students $(83.4 \%)$ and nurse researchers $(87.7 \%)$ from their unit and the university. $16(17.4 \%)$ of the students did not expect to collaborate with research staff after completing their Master of Science in Nursing education (see Table 7). 
Table 5. MSN-student's expectations to participate in specific nursing research-related tasks

\begin{tabular}{ll}
\hline Total & N = 92 (\%) \\
\hline I expect to: & 69 (75.0\%) \\
Participate in a research project & $80(87.0 \%)$ \\
Get an idea for a research project & $63(68.5 \%)$ \\
Design a research project & 62 (67.4\%) \\
Conduct a research project & $70(76.1 \%)$ \\
Use qualitative methods and analysis & $27(29.3 \%)$ \\
Use statistical analysis & $81(88.0 \%)$ \\
Conduct literature reviews in databases like PubMed and CINAHL & $77(83.7 \%)$ \\
Appraise and analyze research articles in Danish & $75(81.5 \%)$ \\
Appraise and analyze research articles in English & $26(28.3 \%)$ \\
Develop a poster & $62(67.4 \%)$ \\
Develop power point for presentation & $62(67.4 \%)$ \\
Write a professional article & $35(38.0 \%)$ \\
Write a scientific article & $39(42.4 \%)$ \\
Apply for funding for research projects & $43(46.7 \%)$ \\
Engage in project management & $41(44.6 \%)$ \\
\hline Develop clinical guidelines &
\end{tabular}

Table 6. MSN-student's expectations to further develop their research knowledge and competencies

\begin{tabular}{ll}
\hline I expect to further develop my research knowledge and competencies & $\mathbf{N}=\mathbf{9 2}(\mathbf{\%})$ \\
\hline No & $2(2.2 \%)$ \\
Yes & $82(89.1 \%)$ \\
No response & $8(8.6 \%)$ \\
If yes, in which areas: & $44(53.6 \%)$ \\
Research design & $34(41.5 \%)$ \\
Research methodology & $60(73.2 \%)$ \\
Qualitative research methods & $63(76.8 \%)$ \\
Qualitative analysis & $35(42.7 \%)$ \\
Quantitative research methods & $27(32.9 \%)$ \\
Statistical analysis & \\
\hline
\end{tabular}

Table 7. MSN-students' expectations of research collaboration

\begin{tabular}{ll}
\hline $\begin{array}{l}\text { I expect to perform nursing research related } \\
\text { tasks in collaboration with research personal }\end{array}$ & $\mathbf{N}=\mathbf{9 2}(\mathbf{\% )}$ \\
\hline No & $16(17.4 \%)$ \\
Yes & $73(79.3 \%)$ \\
No response & $3(3.3 \%)$ \\
If yes, with whom: & \\
PhD students & $61(83.4 \%)$ \\
Nurse researchers & $64(87.7 \%)$ \\
\hline
\end{tabular}

The primary sources of motivation for the MSN-students to participate in nursing research-related tasks were inner motivation $(89.1 \%)$ and management support (80.4\%). About half Published by Sciedu Press of the MSN-students were motivated through clinical guidance $(54.3 \%)$ and support from colleagues (48.9\%), while only $34(37.0 \%)$ of the MSN-students expected role models to motivate them to engage in nursing research-related tasks (see Table 8).

Table 8. MSN-students' sources of motivation

\begin{tabular}{ll}
\hline I expect to be motivated by: & $\mathbf{N}=\mathbf{9 2}(\mathbf{\%})$ \\
\hline Inner motivation & $82(89.1 \%)$ \\
Role models & $34(37.0 \%)$ \\
Clinical guidance & $50(54.3 \%)$ \\
Support from colleagues & $45(48.9 \%)$ \\
Support from management & $74(80.4 \%)$ \\
\hline
\end{tabular}




\section{Discussion}

The results from this study showed that 89 (96.7\%) of the Master of Science in Nursing (MSN) students expected their participation in research-related tasks in clinical nursing to strengthen the nursing profession. This is in line with a study by Graue and colleagues. ${ }^{[25]}$ By means of narrative self-reported reflections among nurses participating in advanced level education an, the core theme of "a change in participants' perception of their professional position", which included the sub-themes "a greater knowledge base enhancing professional confidence" and "a more equal position within the professional team", was discovered. ${ }^{[25]}$ The core theme and sub-themes described how the students experienced a strengthening of their professional impact through the application of evidence in clinical practice, which also led to increased recognition among other health professionals. ${ }^{[25]}$ However, other studies ${ }^{[3,10]}$ found that the barriers and resistance from nursing colleagues and other staff were detrimental to nurses' possibilities for focusing on nursing research-related tasks in clinical practice. Clinical nursing practice culture prioritizes direct patient care and fellow nursing colleagues perceive tasks that are unrelated to patient care as deviant from the norm. ${ }^{[3,10]}$ Strengthening the nursing profession is an academic point of view, which is not necessarily shared by the other nurses in clinical practice, where patient care is regarded as the most important feature. ${ }^{[3]}$ However, strengthening the nursing profession through enhanced knowledge and recognition from other health professionals are important factors in the development of a nursing research culture in clinical practice. ${ }^{[26]}$ In an analysis of the concept of nursing research culture in clinical nursing practice, Berthelsen and Hølge-Hazelton ${ }^{[26]}$ determined "academic thinking and socialization" and "acceptance by colleagues and management" to be two of five defining attributes of a nursing research culture.

In our study, the majority of MSN-students ( $(\mathrm{N}=90 ; 98.8 \%)$ were confident in the need for and necessity of researchrelated tasks in their units and $82(89.1 \%)$ MSN-students were driven by a high level of inner motivation. The MSNstudents $(\mathrm{N}=91 ; 98.9 \%)$ also felt certain that the nursing research-related tasks could lead to an improvement in patient care. Improving practice and patient care are key motivators for nurses deciding to participate in education at the master's level. ${ }^{[19,25]}$ In an ethnographic study of narratives from semi-structured interviews with 37 nurses who had master's degrees in clinical nursing, Zahran ${ }^{[19]}$ found that "developing practice" was a major motivation. The nurses explained the perception of a master's degree as a facilitator for practice development, and taking a master's degree was inspired by a desire to improve direct patient care. ${ }^{[19]}$ Graue and colleagues ${ }^{[25]}$ found the theme of "an expanded perspective of practice and higher level of reflection" to be important for nurses enrolled in a master's level nursing education. The nurses in the study by Graue and colleagues ${ }^{[25]}$ described how expanded perspectives enhanced their abilities to solve problems, which would eventually result in safer patient care. Implementation of research knowledge in clincal practice to improve patient care and enhance evidence-based practice is one of the most difficult aspects in research. Several cross-sectional surveys investigating barriers to nurses' research utilization in clinical practice have found "there is insufficient time on the job to implement new ideas" and "the facilities are inadequate for implementations" to be among the top five barriers. ${ }^{[27-29]}$ Lack of authority to change practice has also been found to be a significant barrier for nurses' research utilization ${ }^{[30,31]}$ because of difficulties with management components. ${ }^{[31]}$

Our results showed that MSN-students expressed high expectations regarding possibilities for participation in nursing research-related tasks in daily clinical practice after completing their education. However, only 22 (23.9\%) of the students had secured employments after completing their education, and just over half of the MSN-students $(\mathrm{N}=12$; $54.5 \%$ ) were secured employment in basic nursing positions that had no academic requirements. Only seven of the 92 participating students had secured employment in positions including research-related tasks, such as clinical nurse specialist, clinical development nurse and research assistant, after finishing their Master of Science in Nursing education. This could indicate that the nurse managers who employ nurses with a Master of Science in Nursing degree are not necessarily aware of the potential benefits of recruiting staff with academic skills. ${ }^{[32]}$ Pegram and colleagues ${ }^{[33]}$ acknowledged this issue in a review and argued that nurse managers have often been in the same management position for years with no opportunities for further education at an academic level. The lack of academic skills and competencies among nurse managers could also be a barrier to acknowledging the relevance and importance of using nursing research-related tasks in clinical practice. ${ }^{[34]}$ Another explanation for the lack of academic positions in clinical practice could be the nurse managers' general concerns of maintaining leadership with a focus on economics and logistics. ${ }^{[35]}$ The possible ambiguity of nurse managers employing nurses with a Master of Science in Nursing degree could be in line with the results of this study, showing that the students (35.9\%) expected to be allocated time and money to participate in research-related tasks. This suggests that the students already have some knowledge of the circumstances of daily practice. However, the students expect their nurse leaders (77.2\%) and head man- 
agement $(72.8 \%)$ to allow them to spend time on research tasks. In a descriptive survey by Linton and Prasun ${ }^{[36]}$ investigating 286 practicing nurses' attitudes and knowledge of evidence-based practice, the authors suggest that nurse managers have to be aware of the need for creating a culture supporting evidence-based practice in order to move towards facilitating and achieving improvements in patient care. This opinion is supported by Hølge-Hazelton and colleagues, ${ }^{\text {[32] }}$ who argue that nurse managers should accept that participation in research is fundamental for the success of a culture of evidence-based nursing care.

\subsection{Strengths and Limitations}

All data were collected from students enrolled at the Master of Science in Nursing education at a single Danish university. Even though the respondents were considered representative of the population under investigation there is a risk of selection bias in the study. This could have been avoided by collecting data from other Danish universities educating nurses at the Master of Science level; however, none of the other educations in Denmark has similar learning objectives or teaching seminars, rendering such a comparison less reliable. Although the number of invited participants was limited to students enrolled in the education on third semester the year of 2017, our participation rate was high (79.3\%), which increases the validity of the study.

The questionnaires were completed anonymously, which reduces response bias. However, questionnaires relying on self-reported data are often criticized for having a low validity and for decreasing the quality of the data. ${ }^{[37,38]}$ In our study, the students filled in the questionnaires themselves.

\section{Conclusion}

The Master of Science in Nursing students showed high expectations regarding the possibilities of participation in nursing research-related tasks in their postgraduate daily clin- ical practice. The key motivator for the Master of Science in Nursing students was their conviction that nursing researchrelated tasks could improve patient care and further develop clinical practice. The Master of Science in Nursing students were confident that research participation would strengthen the nursing profession and lead to a higher knowledge abstraction and professional confidence, as well as enhanced recognition from other health professionals. However, the Master of Science in Nursing students' enthusiasm could be blocked in clinical practice by lack of acceptance from colleagues and other staff and finally by lack of authority to change practice. Furthermore, the students low priority for statistical knowledge could bring complications in designing and conducting studies, why supervision could be needed in this area. Only seven of 92 Master of Science in Nursing students had secured employment in academic positions after graduation and they did not expect the nurse management to allocate time and resources for them to engage in research. The findings of this study indicate a need to prepare clinical practice settings for academic nurses through an understanding of the necessity of their presence and competencies.

In future research we will investigate the educated Master of Science in Nursing graduates' experiences of actually participating in, and utilizing, nursing research-related tasks in clinical practice, through a qualitative as well as quantitative cohort study. Additionally our future research will focus on academic nurses' educated from other Universities in Denmark, to explore their research utilization and how they manage to change clinical practice through evidence-based nursing.

\section{ACKNOWLEDGeMENTS}

We would like to thank the MSN-students who participated in this study, for your time and efforts.

\section{CONFLicts OF INTEREST Disclosure}

The authors declare that there is no conflict of interest.

\section{REFERENCES}

[1] Loke JCF, Laurenson MC, Lee KW. Embracing a culture in conducting research requires more than nurses' enthusiasm. Nurse Educ Today. 2014; 34(1): 132-137. PMid:23031532 https://doi.org/ 10.1016/j .nedt. 2012.09.006

[2] Brown CE, Ecoff L, Kim SC, et al. Multi-institutional study of barriers to research utilisation and evidence-based practice among hospital nurses. J Clin Nurs. 2010; 19(13-14): 1944-1951. PMid:20920021 https://doi.org/10.1111/j.1365-2702.2009.03184.x

[3] Van Oostveen CJ, Goedhart NS, Francke AL, et al. Combining clinical practice and academic work in nursing: A qualitative study about perceived importance, facilitators and barriers regarding clinical academic careers for nurses in university hospitals. J Clin Nurs. 2017; 26(23-24): 4973-4984. PMid:28793367 https://doi.org/10.1

Published by Sciedu Press 111/jocn. 13996

[4] Kajermo KN, Boström AM, Thompson DS, et al. The BARRIERS scale - the barriers to research utilization scale: A systematic review. Implem Science. 2010; 5: 32. PMid:20420696 https: //doi.org/10.1186/1748-5908-5-32

[5] Glacken M, Chaney D. Perceived barriers and facilitators to implementing research findings in the Irish practice setting. J Clin Nurs. 2004; 13(6): 731-740. PMid:15317513 https://doi.org/10.1 $111 / j .1365-2702.2004 .00941 . x$

[6] Roxburgh M. An exploration of factors which constrain nurses from research participation. J Clin Nurs. 2006; 15(5): 535-545. PMid:16629962 https://doi.org/10.1111/j.1365-2702. 20 $06.01374 . \mathrm{x}$

[7] Higgins G, Spencer RL, Kane R. A systematic review of the expe- 
riences and perceptions of the newly qualified nurse in the United Kingdom. Nurse Educ Today. 2010; 30(6): 499-508. PMid:19939524 https://doi.org/10.1016/j.nedt.2009.10.017

[8] Renolen Å, Høye S, Hjälmhult E, et al. "Keeping on track" - Hospital nurses' struggles with maintaining workflow while seeking to integrate evidence-based practice into their daily work: A grounded theory study. Int J Nurs Stud. 2018; 77: 179-188. PMid:29100200 https://doi.org/10.1016/j.ijnurstu.2017.09.006

[9] Berthelsen CB, Hølge-Hazelton B. Orthopaedic nurses' attitudes towards clinical nursing research - A cross-sectional survey. Int J Orthop Trauma Nurs. PMid:25846220 2015; 19(2): 74-84. https : //doi.org/10.1016/j.ijotn.2014.10.004

[10] Thompson DS, O'Leary K, Jensen E, et al. The relationship between busyness and research utilization: it is about time. J Clin Nurs. 2008; 17(4): 539-548. PMid:18205684 https://doi.org/10.1111/j. 1365-2702.2007.01981.x

[11] Stimpfel AW, Sloane DM, McHugh MD, et al. Hospitals Known for Nursing Excellence Associated with Better Hospital Experience for Patients. Health Serv Res. 2016; 51(3): 1120-1134. PMid:26369862 https://doi.org/10.1111/1475-6773.12357

[12] Aiken LH, Clarke SP, Sloane DM, et al. Hospital nurse staffing and patient mortality, nurse burnout, and job dissatisfaction. JAMA. 2002; 288(16): 1987-1993. PMid:12387650 https ://doi.org/10.100 1/jama.288.16.1987

[13] Breimaier HE, Halfens RJ, Lohrmann C. Nurses' wishes, knowledge, attitudes and perceived barriers on implementing research findings into practice among graduate nurses in Austria. J Clin Nurs. 2011; 20(11-12): 1744-1756. PMid:21362075 https://doi.org/10.1 $111 / j \cdot 1365-2702.2010 .03491 . x$

[14] Orton ML, Andersson Å, Wallin L, et al. Potential Benefits of Hiring PhD Prepared Nurses to Provide Patient Care. J Nurs Manag. 2019; 27(5): 955-962. PMid:30656787 https://doi.org/10.1111/jo $\mathrm{nm} .12750$

[15] Chan GK, Barnason S, Dakin CL, et al. Barriers and Perceived Needs for Understanding and Using Research Among Emergency Nurses. J Emerg Nurs. 2011; 37(1): 24-31. PMid:21237364 https: //doi.org/10.1016/j.jen.2009.11.016

[16] Drennan J. Professional and academic destination of masters in nursing graduates: A national survey. Nurse Educ Today. 2008; 28(6): 751-759. PMid:18242790 https://doi.org/10.1016/j . nedt. 2007.12.003

[17] Cotterill-Walker SM. Where is the evidence that master's level nursing education makes a difference to patient care? A literature review. Nurse Educ Today. 2012; 32(1): 57-64. PMid:21371793 https://doi.org/10.1016/j.nedt.2011.02.001

[18] Hardwick S, Jordan S. The impact of part-time post-registration degrees on practice. J Adv Nurs. 2002; 38(5): 524-535. PMid:12028286 https://doi.org/10.1046/j.1365-2648.2002.02214.x

[19] Zahran Z. Master's level education in Jordan: A qualitative study of key motivational factors and perceived impact on practice. Nurse Educ Today. 2013; 33(9): 1051-1056. PMid:22583814 https: //doi.org/10.1016/j.nedt.2012.04.007

[20] Polit DF, Beck CT. Nursing Research: Generating and Assessing Evidence for Nursing Practice (10th Edition). Wolthers Kluwer; 2018.

[21] Akerjordet K, Lode K, Severinsson E. Clinical nurses' research capacity in a Norwegian university hospital: part 2. J Nurs Manag. 2012; 20(6): 824-832. PMid:22967300 https://doi.org/10.1 $111 / j .1365-2834.2012 .01473 . x$

[22] Funk SG, Champagne MT, Wiese RA, et al. Barriers: The barriers to research utilization scale. Appl Nurs Res. 1991; 4(1): 39-45. https://doi.org/10.1016/S0897-1897(05)80052-7

[23] Jacobson AF, Warner AM, Fleming E, et al. Factors influencing nurses' participation in clinical research. Gastroenterol Nurs. 2008;
31(3): 198-208. PMid:18542021 https://doi.org/10.1097/01 .SGA.0000324112.63532.a2

[24] Parahoo K. Research utilization and research related activities of nurses in Northern Ireland. Int J Nurs Stud. 1998; 35(5): 283-291. https://doi.org/10.1016/S0020-7489(98)00041-8

[25] Graue M, Rasmussen B, Iversen AS, et al. Learning transitions-a descriptive study of nurses' experiences during advanced level nursing education. BMC Nurs. 2015; 14: 30. PMid:25977642 https: //doi.org/10.1186/s12912-015-0080-z

[26] Berthelsen CB, Hølge-Hazelton B. 'Nursing research culture' in the context of clinical nursing practice: addressing a conceptual problem. J Adv Nurs. 2017; 73(5): 1066-1074. PMid:27906467 https://doi.org/10.1111/jan.13229

[27] Alshloul M, Abdullah A, Albashtawy M. Barriers and Facilitates of Research Utilization from the Perspective of Nurses in Asser Region of Saudi Arabia. IJHRI. 2013; 2: 15-26. Retrieved at: http: //www.scienpress. com/Upload/IJHRI/Vol\%202_1_2.pdf

[28] Kocaman G, Seren S, Lash AA, et al. Barriers to research utilisation by staff nurses in a university hospital. J Clin Nurs. 2010; 19(1314): 1908-1918. PMid:20529164 https://doi.org/10.1111/j . 1365-2702.2009.03032.x

[29] Wang LP, Jiang XL, Wang L, et al. Barriers to and Facilitators of Research Utilization: A Survey of Registered Nurses in China. PLOS ONE. 2013; 8(11): e81908. PMid:24312380 https ://doi.org/ 10.1371/journal.pone.0081908

[30] Kc S, Subramaniam PR, Paudel S. Barriers and Facilitators of Utilizing Research Among Nurses in Nepal. J Contin Educ Nurs. 2016; 47(4): 171-179. PMid:27031032 https : //doi .org/10.3928/00 220124-20160322-07

[31] Yava A, Tosun N, Çiçek H, et al. Nurses' perceptions of the barriers to and the facilitators of research utilization in Turkey. Appl Nurs Res. 2009; 22(3): 166-175. PMid:19616164 https ://doi.org/10 $.1016 / j$.apnr. 2007.11.003

[32] Hølge-Hazelton B, Kjerholt M, Berthelsen CB, et al. Integrating nurse researchers in clinical practice - a challenging, but necessary task for nurse leaders. J Nurs Manag. 2016; 24(4): 465-474. PMid:26667268 https://doi.org/10.1111/jonm.12345

[33] Pegram AM, Grainger M, Sigsworth J, et al. Strengthening the role of the ward manager: a review of the literature. J Nurs Manag. 2014; 22(6): 685-696. PMid:24815559 https ://doi .org/10.1111/jo $\mathrm{nm} .12047$

[34] Pitkänen A, Kuronen M, Pukuri T, et al. Developing nurses' capabilities to deputize for ward sisters. Int J Psychiatr Nurs Res. 2004; 11(2): 235-239. PMid:15009501 https://doi.org/10.1111/j . $1365-2850.2003 .00670 . x$

[35] Tengblad S. The Work of Managers. Towards a Practice Theory of Management. (S. Tengblad, Red.). Oxford: Oxord University Press; 2012. https://doi .org/10.1093/acprof : oso/978019 9639724.003 .0018

[36] Linton MJ, Prasun MA. Evidence-based practice: collaboration between education and nursing management. J Nurs Manag. 2013; 21(1): 5-16. PMid:23339491 https://doi.org/10.1111/j.13 65-2834.2012.01440.x

[37] Guyatt GH, Oxman AD, Vist G, et al. GRADE guidelines: 4. Rating the quality of evidence-study limitations (risk of bias). J Clin Epidemiol. 2011; 64(4): 407-415. PMid:21247734 https : //doi.org/10.1016/j.jclinepi.2010.07.017

[38] von Elm E, Altman DG, Egger M, et al. The Strengthening the Reporting of Observational Studies in Epidemiology (STROBE) statement: guidelines for reporting observational studies. The Lancet. 2007; 370(9596): 1453-1457. https ://doi.org/10.1016/S0140-673 6(07) 61602-x 